\title{
Characterizing Viscoelastic Property of Soft Tissue Over the Hip as a Risk Factor of Pressure Ulcer
}

\author{
Kitaek Lim, PT, BPT, Seung-su Kim, PT, BPT, Woochol Joseph Choi, PT, PhD \\ Injury Prevention and Biomechanics Laboratory, Department of Physical Therapy, Yonsei University, Wonju, Korea
}

\author{
Article Info \\ Received January 5, 2021 \\ Revised January 19, 2021 \\ Accepted January 21, 2021

\section{Corresponding Author \\ E-mail: wcjchoi@yonsei.ac.kr \\ https://orcid.org/0000-0002-6623-3806} \\ Woochol Joseph Choi
}

\section{Key Words \\ Creep response \\ Pressure ulcer \\ Stress relaxation \\ Viscoelasticity}

Background: A pressure ulcer is common in soft tissue over the greater trochanter (GT) in side-lying position, and sustained tissue deformation induced by the prolonged external force is a primary cause, which can be discussed with soft tissues' viscoelastic properties (i.e., stress relaxation, creep response).

Objects: Using an automated hand-held indentation device, we measured the viscoelastic properties of soft tissue over the hip area, in order to examine how the properties are affected by site with respect to the GT.

Methods: Twenty participants (15 males and 5 females) who aged from 21 to 32 were participated. An automated hand-held indentation device was used to measure the stress relaxation time and creep response. Trials were acquired for three different locations with respect to the GT (i.e., right over the GT, $6 \mathrm{~cm}$ anterior or posterior to the GT). For each location, five trials were acquired and averaged for data analyses.

Results: Soft tissues' stress relaxation time and creep response were associated with site ( $F=$ $23.98, p<0.005 ; F=24.09, p<0.005$; respectively). The stress relaxation time was greatest at posterior gluteal region (19.22 $\pm 2.49 \mathrm{~ms})$, and followed by anterior region (15.39 \pm $2.47 \mathrm{~ms})$ and right over the GT $(14.40 \pm 3.18 \mathrm{~ms})$. Similarly, creep response was greatest at posterior gluteal region (1.16 \pm 0.14$)$, and followed by anterior region $(0.95 \pm 0.14)$ and right over the GT $(0.89 \pm 0.18)$.

Conclusion: Our results showed that the stress relaxation and creep were greatest at the posterior gluteal region and least at right over the GT, indicating that the gluteal soft tissue is more protective to the prolonged external force, when compared to the trochanteric soft tissue. The results suggest that a risk of pressure ulcer over the GT may decrease with slightly posteriorly rotated side-lying position.

\section{INTRODUCTION}

A pressure ulcer is common in nursing home residents. National Nursing Home Survey has shown that one of ten residents suffer from pressure-related injuries [1]. As a result of pressure ulcer, several infectious complications may occur (i.e., cellulitis, bacteremia, and sepsis) and these can lead the residents to death. While prognosis of pressure ulcer isn't bad, the risk of mortality of pressure ulcer can increase about $50 \%$ due to such complications [2-4].

A pressure ulcer is defined as an injury to the skin and underlying soft tissues over a bony prominence, that develops as a result of prolonged external load. Body sites vulnerable to the pressure ulcer include hip, back, ankle, and buttock, highly depending on body positions. In particular, soft tissue over the greater trochanter (GT) is the most vulnerable in side-lying position [5].

Research has shown that pressure ulcer is initiated by ischemia, where cellular metabolism declines due to limited oxygen supply [6-8], and develops through ischemia-reperfusion injury or reoxygenation injury, where soft tissue damage occurs due to inflammatory reaction $[9,10]$. Furthermore, Ceelen et al. [11] conducted experiments with an animal model to measure soft tissue damage after 2 hour-long compression. They found that a positive relationship between soft tissue damage and tissue deformation induced by the prolonged compression, sug- 
gesting that sustained tissue deformation would be a risk factor of pressure ulcer.

Stress relaxation and creep response are unique, time-dependent phenomena observed when biological materials (i.e., muscle, ligament, tendon, cartilage or skin) are subject to the external load (i.e., compression or pulling force). The phenomena occurs because the biological materials are viscoelastic due to water and collagen content inside, and determine the speed and degree of tissue deformation. The stress relaxation is an ability to decrease internal stress caused by compression, and the greater stress relaxation time materials have, the more resistant to redistribution of the stress (thereby more time is required to deform, lowering the risk of pressure ulcer). Similarly, the creep time can be defined as the time it takes to reach final equilibrium strain when the constant load is applied to the tissue, and materials with greater creep time are likely to have greater resistance to deformation, lowering the pressure ulcer risk. These viscoelastic properties have been commonly used in animal studies to address pressure ulcer [12-14]. Technology is available to measure these properties by analyzing responses of soft tissue to small tapping force. When the tapping force is applied, soft tissue vibrates with alteration of compression and expansion. This oscillation decays over time, and the speed and depth of compression (or oscillation) depend on the viscoelastic properties of soft tissue. By analyzing this time series of deformation, velocity and acceleration data, stress relaxation and creep response of soft tissue can be estimated.

Against this background, we measured stress relaxation and creep response of soft tissue over the hip area as biomarkers of pressure ulcer. We then examined how these are affected by sites with respect to the GT.

\section{MATERIALS AND METHODS}

\section{Participants}

Twenty individuals ( 15 males and 5 females [aged between 21 and 32]) were recruited. Demographic information is provided in Table 1. Exclusion criteria included musculoskeletal injuries, including but not limited to, abrasion, laceration, burn, fractures, contusion over the hip area. All participants provided signed consent forms. The study protocol has been approved by the Institutional Review Board in Yonsei University Mirae campus.

\section{Experimental Protocol and Data Analysis}

Participants lay sideways exposing the skin of the lateral aspect of the hip (Figure 1A). With respect to the GT, three points with an interval of $6 \mathrm{~cm}$ were marked on the skin via a watersoluble pen (Figure 1B). We then used an automated hand-held indentation device (MyotonPRO; Myoton AS, Tallinn, Estonia) to measure viscoelastic properties of soft tissue over the three

Table 1. Demographic information

\begin{tabular}{lc}
\hline Variables & Participants \\
\hline Age $(\mathrm{y})$ & $24.4 \pm 2.4$ \\
Height $(\mathrm{cm})$ & $171.1 \pm 8.9$ \\
Weight $(\mathrm{kg})$ & $78.0 \pm 14.0$ \\
\hline
\end{tabular}

Values are presented as mean \pm standard deviation.
A

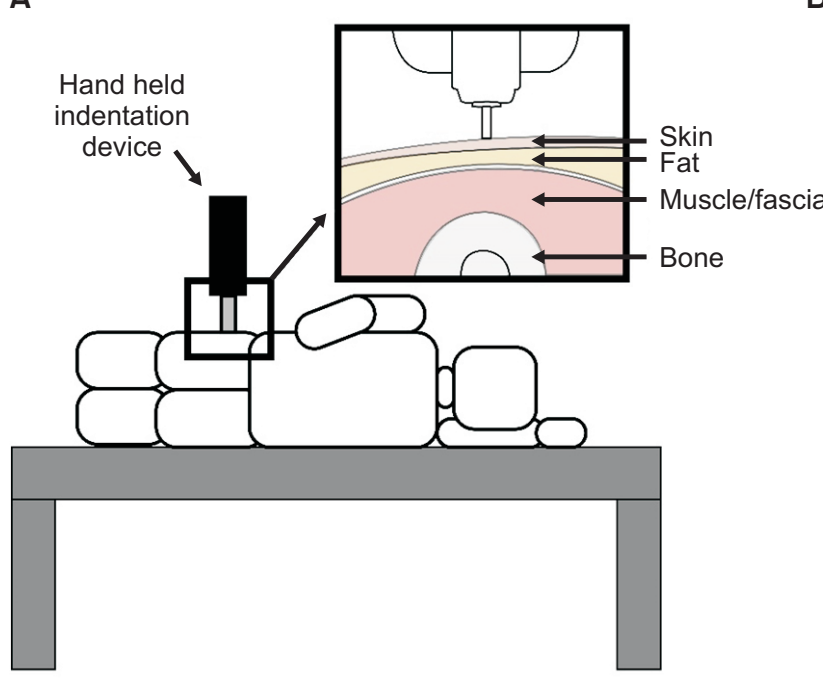

B

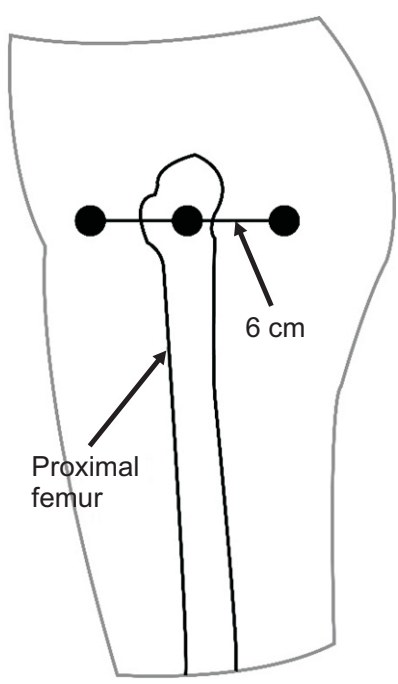

Figure 1. (A) Experimental setup, (B) measurement sites with respect to the greater trochanter. 
points. The device recorded vibration of soft tissue after applying a low taping force $(0.4 \mathrm{~N})$ to the skin, and calculated stress relaxation time and a ratio of "stress relaxation time" to "time to cause maximum deformation" (creep response). Measurement of coefficient of variation (CV) of the device provided in the manual shows that the CV of stress relaxation and creep were $1.2 \%$ and $1.5 \%$, respectively. Furthermore, several research studies support accuracy and repeatability of the methodology of the device [15-17]. Two trained physiotherapists (practiced at least 1 hour for measurements) measured the participants' right hip and five trials were acquired for each location (tap time was $15 \mathrm{~ms}$ with $1 \mathrm{~ms}$ intervals) and averaged for data analyses.

Repeated measures ANOVA was used to test whether the outcome variables were associated with site with respect to the GT (3 levels). When a main effect was significant, pairwise comparisons were conducted using Bonferroni correction with alpha level at $0.017(0.05 / 3)$.

\section{RESULTS}

Stress relaxation was associated with site $(\mathrm{F}=23.98, \mathrm{p}<$ 0.005). The stress relaxation time differed across three sites with respect to the GT, being greatest $(19.2 \pm 2.49 \mathrm{~ms})$ at the posterior gluteal region and least $(14.4 \pm 3.18 \mathrm{~ms})$ at right over the GT (Figure 2A).

Similar trends were observed for creep response, and creep response was associated with site $(\mathrm{F}=24.09, \mathrm{p}<0.005)$. The creep response differed across three sites over the hip region, being greatest $(1.16 \pm 0.14)$ at the posterior gluteal region and least $(0.89 \pm 0.18)$ at right over the GT (Figure $2 \mathrm{~B})$.

\section{DISCUSSION}

The purpose of this study was to examine whether the viscoelastic properties (stress relaxation, creep) were affected by site, in order to discuss a risk of pressure ulcer with side-lying position. We found that the stress relaxation time and creep response were greatest at posterior gluteal region and least at right over the GT. This indicates that the gluteal soft tissue is more resistant to tissue deformation induced by the prolonged external force when compared to the trochanteric soft tissue, suggesting that a risk of pressure ulcer over the GT may decrease with slightly posteriorly rotated side-lying position. This finding supports the repositioning guidelines for the individuals who are bedridden [18]. The guidelines suggest side-lying position with body rotation 30 degrees posterior would reduce the incidence of pressure ulcer in hospitalized patients when compared to side-lying position with a pelvis perpendicular to the horizontal line, where the GT contacts the bed directly [19].

A potential reason why the viscoelastic properties differed across sites might be explained, in part, by varying properties and composition of soft tissue over the hip area [6,20]. The soft tissue may include skin, fat, muscle and fascia, and each tissue layer has different viscoelastic properties (i.e., muscle is more viscoelastistic than fat). Furthermore, distribution (thickness) of each layer depends on site with respect to the GT (more muscle and adipose tissue in posterior [gluteal] region than in anterior or right over the GT). This variability results in changes in soft tissue properties over the hip area.
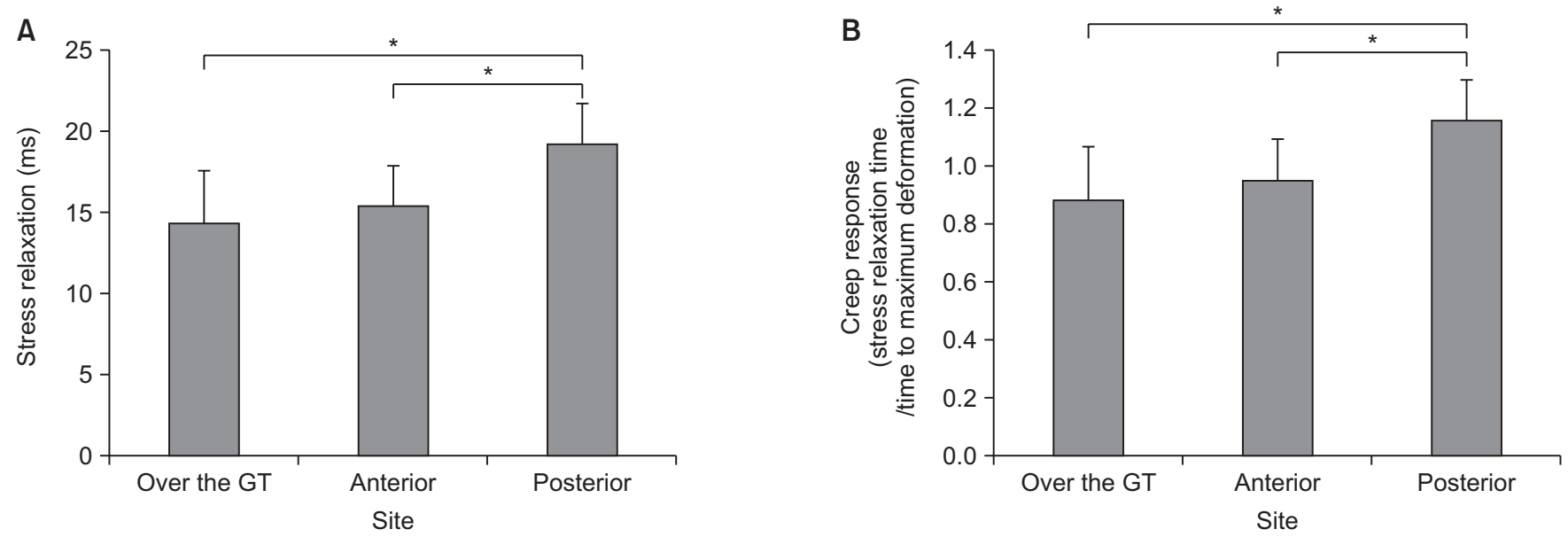

Figure 2. Effect of site on the stress relaxation (A) and creep response (B) over the hip area. 
Our study has several limitations. First, the stress relaxation and creep response is time-dependent, but temperaturedependent as well. However, we did not consider room or participants' skin temperature during data collection. Second, previous systematic reviews showed that age, mobility and activity levels are risk factors of pressure ulcer [21,22]. However, these were not considered in this study. Future studies should include these factors for better understanding of how the viscoelastic properties over the hip area are affected by sites.

\section{CONCLUSIONS}

The stress relaxation time and creep response were greatest at the posterior gluteal region and least right over the GT, indicating that the gluteal soft tissue is more resistant to tissue deformation induced by the prolonged external load, when compared to the trochanteric soft tissue. The results suggest that a risk of pressure ulcer over the GT may decrease with slightly posteriorly rotated side-lying position.

\section{ACKNOWLEDGEMENTS}

This study was supported by the "Brain Korea 21 FOUR Project”, the Korean Research Foundation for Department of Physical Therapy in the Graduate School of Yonsei University. Authors thank Seohyun Kim for her help in data collection.

\section{CONFLICTS OF INTEREST}

No potential conflict of interest relevant to this article was reported.

\section{AUTHOR CONTRIBUTIONS}

Conceptualization: KL, WJC. Investigation: KL, SK. Supervision: WJC. Writing - original draft: KL. Writing - review \& editing: KL, WJC.

\section{ORCID}

Kitaek Lim, https://orcid.org/0000-0001-5475-3196

Seung-su Kim, https://orcid.org/0000-0002-8735-3794

\section{REFERENCES}

1. Howard DL, Taylor YJ. Racial and gender differences in pressure ulcer development among nursing home residents in the Southeastern United States. J Women Aging 2009;21(4):26678.

2. Allman RM. Pressure ulcers among the elderly. N Engl J Med 1989;320(13):850-3.

3. Bryan CS, Dew CE, Reynolds KL. Bacteremia associated with decubitus ulcers. Arch Intern Med 1983;143(11):2093-5.

4. Galpin JE, Chow AW, Bayer AS, Guze LB. Sepsis associated with decubitus ulcers. Am J Med 1976;61(3):346-50.

5. Zeller JL, Lynm C, Glass RM. JAMA patient page. Pressure ulcers. JAMA 2006;296(8):1020.

6. Daniel RK, Priest DL, Wheatley DC. Etiologic factors in pressure sores: an experimental model. Arch Phys Med Rehabil 1981;62(10):492-8.

7. Dinsdale SM. Decubitus ulcers: role of pressure and friction in causation. Arch Phys Med Rehabil 1974;55(4):147-52.

8. Kosiak M. Etiology and pathology of ischemic ulcers. Arch Phys Med Rehabil 1959;40(2):62-9.

9. Grisotto PC, dos Santos AC, Coutinho-Netto J, Cherri J, Piccinato $\mathrm{CE}$. Indicators of oxidative injury and alterations of the cell membrane in the skeletal muscle of rats submitted to ischemia and reperfusion. J Surg Res 2000;92(1):1-6.

10. Peirce SM, Skalak TC, Rodeheaver GT. Ischemia-reperfusion injury in chronic pressure ulcer formation: a skin model in the rat. Wound Repair Regen 2000;8(1):68-76.

11. Ceelen KK, Stekelenburg A, Loerakker S, Strijkers GJ, Bader DL, Nicolay K, et al. Compression-induced damage and internal tissue strains are related. J Biomech 2008;41(16):3399404.

12. Simon GA, Maibach HI. The pig as an experimental animal model of percutaneous permeation in man: qualitative and quantitative observations--an overview. Skin Pharmacol Appl Skin Physiol 2000;13(5):229-34.

13. Palevski A, Glaich I, Portnoy S, Linder-Ganz E, Gefen A. Stress relaxation of porcine gluteus muscle subjected to sudden transverse deformation as related to pressure sore modeling. J Biomech Eng 2006;128(5):782-7.

14. Gefen A, Haberman E. Viscoelastic properties of ovine adipose tissue covering the gluteus muscles. J Biomech Eng 2007; 129(6):924-30.

15. Chuang LL, Wu CY, Lin KC. Reliability, validity, and respon- 
siveness of myotonometric measurement of muscle tone, elasticity, and stiffness in patients with stroke. Arch Phys Med Rehabil 2012;93(3):532-40.

16. Ko CY, Choi HJ, Ryu J, Kim G. Between-day reliability of MyotonPRO for the non-invasive measurement of muscle material properties in the lower extremities of patients with a chronic spinal cord injury. J Biomech 2018;73:60-5.

17. Lo WLA, Zhao JL, Chen L, Lei D, Huang DF, Tong KF. Betweendays intra-rater reliability with a hand held myotonometer to quantify muscle tone in the acute stroke population. Sci Rep 2017;7(1):14173.

18. Haesler E. Prevention and treatment of pressure ulcers: clinical practice guideline. 2nd ed. Perth: Cambridge Media; 2014.
19. Moore Z, Cowman S, Conroy RM. A randomised controlled clinical trial of repositioning, using the $30^{\circ}$ tilt, for the prevention of pressure ulcers. J Clin Nurs 2011;20(17-18):263344.

20. Mak AF, Zhang M, Tam EW. Biomechanics of pressure ulcer in body tissues interacting with external forces during locomotion. Annu Rev Biomed Eng 2010;12:29-53.

21. Coleman S, Gorecki C, Nelson EA, Closs SJ, Defloor T, Halfens $\mathrm{R}$, et al. Patient risk factors for pressure ulcer development: systematic review. Int J Nurs Stud 2013;50(7):974-1003.

22. Alderden J, Rondinelli J, Pepper G, Cummins M, Whitney J. Risk factors for pressure injuries among critical care patients: a systematic review. Int J Nurs Stud 2017;71:97-114. 